\title{
Análise grupal transicional 65
}

\section{Moisés Rodrigues da Silva Júnior 66}

"Um barco parece ser um objeto cujo fim é navegar; mas o seu fim não é navegar, mas chegar a um porto".

Nós navegamos sem a ideia de um porto em que devêssemos nos refugiar. Reproduzimos assim, a aventurosa fórmula dos antigos navegadores:

navegar é preciso,

viver não é preciso...

Viver não é preciso,

O que é necessário é criar"

Livro do Desassossego, por Bernardo Soares, Fernando Pessoa.

A experiência com a psicose e casos graves nos leva a pensar que a gravidade é sempre uma complexidade que eclode de múltiplas maneiras e em diferentes âmbitos: no corpo, no trabalho, nas relações afetivas, sociais cobrando sempre abordagens múltiplas.

Nessas situações o silêncio analítico que colocaria o sujeito em confronto com seus próprios enunciados, aponta para o vazio ou confusão mental que não o remete a outra coisa senão a um nada, colocando a descoberto as impossibilidades de estabelecer relações, construir símbolos, vínculos causais entre os fatos, juntar cisões, tornando exigente a tarefa de enfrentamento à precariedade de elementos subjetivos para expressar a dor vivida.

Sendo portador de uma experiência que não pode ser acessada pela palavra, o sujeito se apresenta ligado ao mundo através da experiência direta, própria às formas primárias de relação com o ambiente, impondo-se então, construir uma clínica em que o manejo passa a ser a forma primordial de intervenção.

Essa passagem exige instrumentos teórico clínicos que permitam a abordagem do complexo campo de experiências pré-linguísticas, em especial fenômenos como a percepção, a comunicação e a criatividade inconsciente.

Cristopher Bollas desde o início dos anos 1990 propõe uma expansão do modelo freudiano de Inconsciente considerando a possibilidade de que a mente inconsciente se expande e é estruturada por matrizes criadas a partir de

65 Trabalho apresentado na mesa "A clínica vincular e suas bordas: o trabalho com grupos " no II Simpósio Bienal SBPSP "Fronteiras da Psicanálise: a clínica em movimento" no dia 22 de agosto de 2020.

66 Médico psicanalista, analista institucional, docente do curso de Psicanálise do Instituo Sedes Sapientiae, diretor de Projetos Terapêuticos. 
fragmentos de ideias, imagens e sentimentos inter relacionados que convergem, e se cristalizam em um processo de continua complexificação que ele denomina genera psíquicos. Cristopher Bollas nessa elaboração parte 2 conceitos freudianos: 1. Apresentação de coisa e 2. Pontos nodais imantados necessariamente em torno de um impasse, insatisfeito, desconhecido, e que exercem um poder de atração sobre materiais psíquicos. Os genera também se comunicam com a mente consciente promovendo a busca de objetos externos que ofereçam a possibilidade de transformação e crescimento.

O foco de interesse do tratamento passa a ser a experiência vivida atual, levando em conta uma subjetividade em movimento de permanente construção.

Trabalhar com projetos liga-se então a essas criações dos genera e sua inapelável ligação com as forças do futuro, com a condição de ser - estar no presente comprometido com um fim almejado. Sua potência advém da mobilização de elementos da vida cotidiana, da imaginação, da fantasia no limite da desrazão e do delírio.

Nesse processo nenhum fato ou escolha pode ser deixado de lado, mesmo as escolhas mais banais, pela cuidadosa recuperação de qualquer traço de originalidade, uma centelha de pensamento, um fragmento evasivo de auto experiencia, levando-se em consideração o que o sujeito nos traz como elementos construtivos, marca de sua singularidade. Entendemos assim a interação entre sujeito e projeto, como irredutível e indissociável.

Tomando como ponto de partida a concepção winiccottiana de grupos, a psicologia do indivíduo e, em especial a integração pessoal, René Kaës cunhou a fórmula "análise grupal transicional". Neste dispositivo o grupo está pensado como uma estrutura de recepção, elaboração, de reparação do traumático e das rupturas sofridas pelo sujeito com o fim de restaurar a capacidade de simbolização, continuidade psíquica e criatividade.

É pela conecção afetiva e a oferta ativa de objetos como instrumentos de cuidado que se estabelecem um apoio para o self como fenômeno processual e também apoio das funções psíquicas que se faz sobre o grupo e a instituição que o grupo mediatiza.

A ideia de apoio inclui a mutualidade, é dizer, que aquele que apoia pode ser apoiado pelo outro: o narcisismo dos pais se apoia sobre o bebê e o bebê, por sua vez, apoia o seu narcisismo sobre os pais. 
A mutualidade se constitui como uma comunicação silenciosa e íntima, estabelecida entre mãe e bebê e que tem um caráter predominantemente corpóreo / sensorial de afetações que o encontro com esse outro determina. Winnicott nos fala de um tipo de comunicação que independe da linguagem e na sua compreensão, a mãe estaria comunicando que é confiável: "o bebê não ouve ou registra a comunicação, mas apenas os efeitos da confiabilidade” (Winnicott,1968).

É a partir da desadaptação da mãe que comete pequenos erros e os corrige cuidando de seu bebê, nesse movimento de pequenas falhas e cuidados, que se funda a comunicação, permitindo ao bebê desenvolver uma sensação de segurança e confiabilidade. Nas palavras de Winnicott:

São as inúmeras falhas, seguidas pelo tipo de cuidados que as corrigem, que acabam por constituir a comunicação (de amor), assentada sobre o fato de haver ali um ser humano que se preocupa (Winnicott, 1968)

Nessa infindável série de acertos e erros se constitui uma "sintonia de afeto" “...seu desenvolvimento é gradual, transformando-se em um estado de intensa sensibilidade no decorrer do tempo... " (Winnicott ,1956).

O primeiro mundo que habitamos tem como condições de existência a confiabilidade e a previsibilidade que constituem no vocabulário winiccottiano, a cobertura: a mãe evita que alguma coisa inesperada surpreenda o bebê interrompendo a sua continuidade de ser; a mãe é confiável quando em meio as necessidades sempre variáveis do bebê mantém regularidade constante e consistente a si mesma e ao ambiente, sendo notável a capacidade de ingressar e sair desse estado tão especial de ser.

Em grupos constituídos por pessoas relativamente não integradas, marcadas pela "súbita retirada de apoio" de uma mãe imprevisível, torna-se imprescindível uma cobertura que lhes provisione confiança para explorar a situação inicial e abrir espaço para a dependência e regressão a estados não integrados. Só apoiados na cobertura proporcionada pelos terapeutas que se constituem neste momento na base do grupo se inicia o processo de integração e a possibilidade de participar de seu primeiro grupo. O grupo é uma conquista do EU SOU, e é uma conquista perigosa, sendo a proteção muito necessária nos estágios iniciais; (sem ela o mundo externo repudiado volta-se contra o novo fenômeno e o ataca.) (Winnicott, 1955). 
Gradualmente e a partir de alguma integração pessoal e com o decorrer do tempo, aquele conjunto de pessoas transforma-se numa espécie de grupo. As técnicas de cobertura podem ser abrandadas e o recente grupo começa um processo de sustentação a partir das primeiras percepções do outro e o nascimento de interesses compartilhados, força fundante (do grupo) e que promove integração no interior de cada indivíduo. Nesse momento já temos o pulsar de vida conectando corações e corpos... os genera psíquicos promovem a busca de objetos externos que ofereçam a possibilidade de transformação. O eixo condutor da atividade de grupo está centrado nas percepções das linhas que se vão traçando na composição de um squiggle comum e compartilhado. Inútil tentar apressar o sentido do processo de construção dos esboços. É o não sentido de Winnicott vital em qualquer processo criativo, científico, artístico ou psicanalítico, exigindo a necessária espera tolerante frente ao não saber. Nesse estágio do processo de criação subjetiva grupal, o coordenador se entrega ao jogar sem exigir-se compreender o sentido do seu jogo ou o sentido do jogo do grupo.

\section{Nós navegamos sem a ideia de um porto em que devêssemos nos refugiar. \\ $\cdots$ \\ O que é necessário é criar"}

O desafio posto aos terapeutas: "não só escutar com a orelha transferencial, mas também com a orelha do real". O transferencial não é objetivo nem subjetivo, mas ambas as coisas ao mesmo tempo. Trata-se de uma ilusão assentada sobre uma situação concreta que se confunde permanentemente com a fantasia gerando as imagens que povoam a zona intermediária.

É preciso esperar para que o gesto criador possa emergir, promovendo o acontecer do self. Este é uma ação que permite o aparecimento do fenômeno de ilusão pelo qual um sentido de realidade é estabelecido: a realidade subjetiva. Se a cobertura grupal é bastante boa se produz no individuo uma ilusão: existe uma realidade externa que corresponde à minha própria capacidade de criar.

Nunca lhe perguntaremos: você criou isto ou isto lhe foi apresentado desde fora". Minha contribuição consiste em pedir que o paradoxo seja aceito, tolerado e respeitado e que não se procure resolvê-lo (Winnicott, 1971). 
Sendo a ilusão grupal uma fase inevitável na constituição do grupo, esperase que se atravesse a mesma, passando por momentos de desilusão que portam consigo uma progressiva aceitação da realidade, tarefa nunca acabada

A clínica é abundante em situações dos efeitos negativos da separação prematura entre Eu e não Eu que alteram a espontaneidade do sujeito e o orienta compulsoriamente a adaptar-se ao desejo do outro que não é a mesma coisa de um genuíno desenvolvimento simbólico. Pode-se prever quão entristecedora e falsa é a situação quando o que ocorre é o contrário disso favorecendo situações de impotência e de vazio.

Winnicott citando Hölderlin:

deixem o homem imperturbado, desde o berço. Não o expulsem do bulbo estreitamente unido do seu ser, não o expulsem da casa protetora de sua infância.... pois só assim ele se tornará homem. O homem é um deus assim que se torna homem. E, sendo um deus, ele é bonito (Hölderlin,1968)

Todo o trabalho realizado é para que os participantes possam encontrar / construir um refúgio contra a luta que se vive fora no mundo. É possível criar-se uma sensação de proteção e sentir-se bem (ou menos mal...) quando se está no grupo. E como contrapartida os pacientes descrevem uma sensação de vazio que para alguns se manifesta como uma raiva quando por algum motivo não podem frequentar o grupo que se converteu numa zona de segurança em que o indivíduo recupera a esperança e torna-se capaz de identificar-se com grupos cada vez mais amplos sem perda da noção de self e com um ganho crescente de espontaneidade.

\author{
"Viver não é preciso \\ O que é necessário é criar"
}

\title{
Referências
}

Bollas C. (1994). Ser un personage:

Psicoanalisis y experiencia del sí mismo. Paidós.

Hölderlin, F. (2012) In:Hipérion ou o eremita na Grécia. São Paulo:

Forense Universitária, 1991

Pessoa F. (1999). Livro do Desassossego. São Paulo: Companhia da Letras

Winnicott, D.W.(1971) Objetos transicionais e fenômenos transicionais. In: 
O brincar e a realidade, Imago, RJ, 1975

(1955) Influências de grupo e a criança desajustada. In:

Privação e delinquência. São Paulo: Martins Fontes, 1987

(1956) A preocupação materna primária. In:

Da pediatria à psicanálise: obras escolhidas. Rio de Janeiro:

Livraria Francisco Alves, 1988

(1968). A comunicação entre o bebê e a mãe e entre a mãe e bebê:

convergências e divergências. In: Os bebês e suas mães. São Paulo:

Martins Fontes, 1994 